\title{
BUSINESS IMPACT ANALYSIS IN THE PROCESS OF BUSINESS CONTINUITY MANAGEMENT
}

\author{
Josef KRAHULEC, Ing. \\ Miroslav JURENKA, Ing. PhD \\ University of Defence, Brno, Czech Republic
}

\section{Introduction}

The article deals with issues of the societal security, especially with the significant process Business Impact Analysis (BIA). It is the process of analysing the organization's activities and impacts that may be caused by a disruption.

The BIA is foundation of the whole process of Business Continuity Management (BCM) that is defined in the British Standard BS 25999 with updating into two new international standards: ISO 22301 (requirements) and ISO 22313 (guidance). By accepting and implementing these standards, the customers and clients can be assured that their business activities will be secured and prepared for treating impacts on the business continuity in the case of disruption. It consists of specific techniques and methods, that help with risk assessment (RA) in the situations, when an impact (structural, financial, economical etc.) could cause a disruption of the organization's activities, stakeholders goodwill or supply of key products and services of the organization (critical activities). Part of the BIA is to establish minimum levels of resources needed to restore critical operations at fixed times and at certain levels. Expression "business" has in this context also reason "activity" not only reason connected with real business activities.

Impact on the organization and their evolution over time is assessed according to the appropriate guidance. Selected guides must be appropriate for the organization; 
guides financial institutions will differ from the guideline government authority. Guidelines for impact assessment may be, for example, financial loss, the impact on service delivery, damage to or loss of reputation, comply with legal or regulatory obligations, etc.

Conclusions from the impact analysis together with risk assessment on disruption of critical activities of an organization are the basis for business continuity management strategies that identify various options and ways to restore critical operations of the organization at the desired time in case of disruption.

The BIA should be reviewed in regular intervals or when there are significant changes in the organization and the environment in which the organization operates $[2,8]$.

\section{Specified Range Of Organization Activities By BIA}

This analysing process should be useful for all organization types, naturally with specific measures. In the case of this article and another specific research is the attention, connected with BIA, focused on the non-profit organizations, such as police, fire brigade, rescue system and another public administration organizations. Of course it is possible to apply this method also for the profit organizations and many others. The specified range of organization activities should:

- identify activities that support the delivery of its key products and services;

- assess the impact, if there is a violation of these activities and the development of these effects over time;

- determine for each identified activity the Maximum Tolerable Period of Disruption (MTPD) or Maximum Tolerable Outage (MTO), after which the implications for the organization are still acceptable. After this process there is a viability of the organization at risk in the case of a supply disruption products or services;

- identify critical activities and prioritize their renewal based on the previous steps of determining the impact of the MTPD for individual activities. For critical activities may be considered activities with the greatest impact in the shortest time. These activities should be restored as soon as possible;

- specify the time required for its recovery (partial or full) level Recovery Time Objective (RTO) for every critical activity. Setting RTO is on management 
decisions. To determine this, it is necessary to consider the associated costs of rehabilitation. The optimal value of RTO can be, when the financial loss caused by disruption of operations, is equal to the cost of its restoration. Specified period of recovery (RTO) critical activities must be less than the (MTPD);

- determine the minimum level of resources needed to rebuild every critical activity. Resources may include, for example, people, buildings, technology, information and service delivery [4].

\section{Business Impact Analysis (BIA) in the Centre Disaster Recovery Planning (DRP)}

Within the scope of the emergency recovery planning in this multistage process, the most important phase is just BIA. The analysis of the impact on businesses is in area with a significant degree of probability, the impact of disruption. In some cases might appear the case connected with the disaster recovery planning, because in the BIA there is an exact classification of estimating the effects of the accident on the organization.

Analysis of the risk-based impact sets the goal of identifying critical business functions with regard to their disruption and is an important point for setting the strategic disaster recovery plan. The next step, according to British Standards of Risk Assessment in the organization, is determination the internal and external threats and risks including operational infrastructure. For the impact analysis is required especially large amount of data for the preparation of questionnaires and it is also necessary to prepare the groundwork for interviews with members of the organization.

Research will further define activities supporting key areas and services of organizations, being identified by impacts, which are caused by the disruption of business activities. Because all of these steps related to the time parameter, it is possible according to specify how long the organization will be able to function during the disruption of their activities and supplies. The BIA process is probably the longest and the most important process of all activities that are concerned with ensuring business continuity. 
The BIA also has the task of categorizing priority business activities for recovery, as well as to identify all internal and external dependencies associated with critical activities set amount of time to restore operations. Furthermore, the BIA deals with determining the impact on the income of the various corporate activities, which are reflected in the accounts. Thus poised conclusions of the analysis and evaluation must be checked and approved by the top management, as the results of this analysis will be provided as the basis for defining organization business continuity [4].

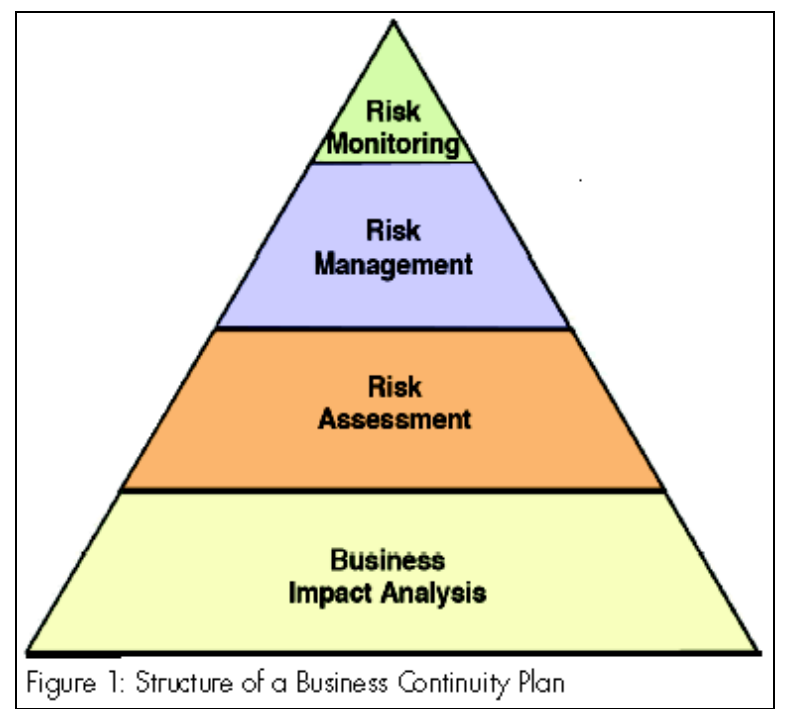

Source: [7]

Picture 1. Possition the BIA in the Business Continuity Plan

Basic framework of BIA:

- to identify the key business processes (processes related to main military activities);

- to determine the requirements of restoration and interdependences;

- to identify impacts on the organisation's functions (also related to military functions);

- to prioritize the business processes and set the restoration requirements. 
Identification of key processes:

- expected suggestions (implementation of new approaches of continuity processes for military area);

- monitoring of stock items (thorough monitoring of stocks of ammunition and military equipment);

- online customer service;

- credit card processing;

- online message board;

- database search (continuously control the military database with focusing on current and future threats);

- create an online catalogue $[3,6]$.

Relationships with key processes in other areas:

- IT management;

- public relations;

- compliance with regulations;

- supply agreements;

- budgeting;

- financial reporting;

- emergency loan $[3,6]$.

The Recovery Time Objective (RTO) is closed to the business process but not in the case of requiring the support of the process. It is also targeted on the continuation of service and time level inside a business process that has to be renewed after disaster influence in appropriate time. The Recovery Point Objective (RPO) is a process in business continuity planning connected with IT service and is focused on the maximum targeted period when data might be lost. RPO describes the age of data in the last available IT reserve for potential renewal. All these analysis steps are really important and purposeful because of its significance related to the security and military area in general and are useful for many types of security processes.

Within the scope of the impact assessment of the organization in disruption of critical activities are taken into account in particular the consequences before causes. 


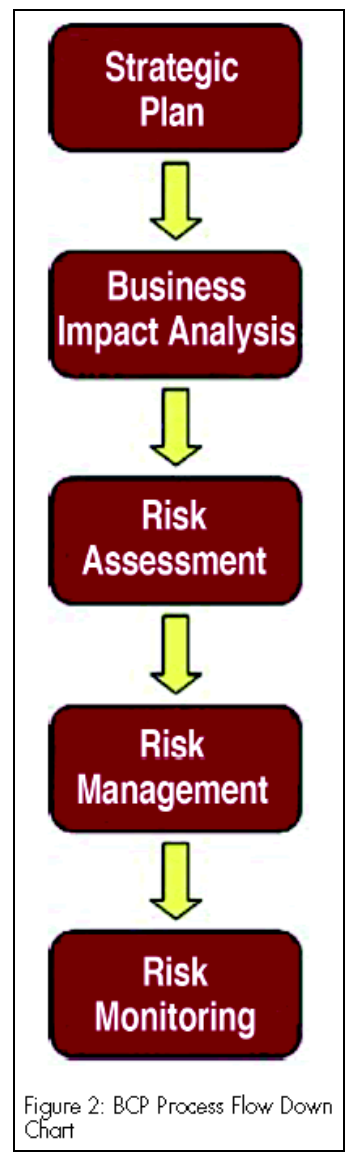

Source: [1]

Picture 2. BCP Process Flow Down Chart

What impact will affect the operation of the organization and its subsequent development is determined by the appropriate guideline. Such guidelines must be appropriate for the organization and guidelines vary from state authority.

The basis for business continuity management strategy, which precisely defines the various options and possibilities for recovery of critical activities of the organization under the relevant time relations, are the outcome of the impact analysis and risk assessment disruption to critical operations of the organization $[3,5]$. 


\section{Key Tips By Implementation Business Impact Analysis}

1) Getting the support of top management (primarily due time for research, as well as a strong overall support of the top management to achieve project goals).

2) Emphasis on business impact analysis process (BIA analysis can be very time consuming for both the actual data collection, as well as for the actual analysis, it is also very important to work with accurate and current information).

3) Flexibility (encourages any adjustment patterns according to the needs of individual organization to facilitate achievement of the set goals) [3, 4].

\section{Conclusion}

The conclusions from the BIA are possible to specify like impact analysis together with risk assessment on disruption of critical activities of an organization. There are the basis for Business Continuity Management (BCM) strategies that identify various options and ways for restoration critical operations of the organization at the desired time in case of disruption.

With BIA are connected specific techniques and methods, which help with risk assessment (RA) in specific impact situations (economical, financial, structural etc.). These impact situations might cause a disruption of the organization's activities, stakeholder's goodwill or supply of key products and services (critical activities).

Problems of impact on the organization and their evolution over time are assessed according to the appropriate guidance. It is necessary to select appropriate guides for the organization. Guidelines for impact assessment might be impact on service delivery, financial loss, damage or loss of reputation, etc.

The topic is intended primarily for profit organizations, but thanks to its versatility, it is also suitable for other types of organizations, including the military. In the case of modification of the evaluation criteria and the method can be applied to the relevant procedures for the police, army and many other companies. 


\section{Used Sources}

[1] BCP Process Flow Down Chart. In: Advantage Business Media [online]. ( 2015 Advantage Business Media. [vid. 17. 02. 2015]. Available from: http://www.cemag.us/ articles/2008/04/integrating-business-continuity-part-strategic-planning

[2] BEAZLEY, Hamilton, Jeremiah BOENISCH a Davòid HARDAN. Continuity management: preserving corporate knowledge and productivity when employees leave. New York: John Wiley, c2002, xvii, 269 p. ISBN 0471219061.

[3] Business and industry portal: Conduct a business impact analysis. Queensland Government [online]. 2014 [cit. 2015-02-27]. Dostupné z: https://www.business. qld.gov.au/business/running/risk-management/risk-management-plan-businessimpact-analysis/conduct-business-impact-anaylsis

[4] Business impactanalysis (BIA) at heart of disaster recovery planning. Computer Weekly. com [online]. 2015 [cit. 2015-02-17]. Dostupné z: http://www.computerweekly.com/ podcast/Business-impact-analysis-BIA-at-heart-of-disaster-recovery-planning

[5] Business impact analysis (BIA). Searchstorage.techtarget.com [online]. 2015 [cit. 2015-02-17]. Dostupné z:http://searchstorage.techtarget.com/definition/businessimpact-analysis

[6] ESTALL, Hilary. Business continuity management systems: implementation and certification to ISO 22301. Swindon, U.K: BCS, the Chartered Institute for IT, 2012. ISBN 9781780171463.

[7] Possition the BIA in the Business Continuity Plan. In: Advantage Business Media [online]. (C) 2015 Advantage Business Media. [vid. 17. 02. 2015]. Available from: http:// www.cemag.us/articles/2008/04/integrating-business-continuity-part-strategicplanning

[8] URBÁNEK, J. F. et al. Crisis Scenarios. Brno: University of Defence, Monika Promotion Ltd. 2013, ISBN 978-80-7231-934-3. 